\title{
Study on Compression Moulding of Continuous Long Quartz Fiber-reinforced PEEK Composite Bar
}

\author{
Baotong Zhuang ${ }^{1, a}$, Fenglei Liu ${ }^{1, b}$, and Shengru Long ${ }^{2, c}$ \\ ${ }^{1}$ AVIC Beijing Aeronautical Manufacturing Technology Research Institute, Beijing 100024,China \\ ${ }^{2}$ Institute of Materials Science \&Technology, Sichuan University, Chengdu 610064,China \\ azbt115@163.com, bliufl625105@sian.com, 'Isrhome@163.com
}

\begin{abstract}
Keywords: Continuous long quartz fiber-reinforced PEEK, Composite bar, Heat compression moulding process

Abstract. The moulding process of 3D-braided PEEK/LQ prepreg is studied by optical microscope, scanning electron microscope and tensile testing machine in this paper. The mechanical property of composite with different fiber content is analyzed as well. The results show that a better impregnation of moulded PEEK resin to the continuous long quartz fiber is obtainedat the moulding temperature of $380^{\circ} \mathrm{C}$. The internal porosity of composite bar decreases as the holding pressure increases. The densest microstructure and no hole is observed inside the composite bar after adding venting inmoulding process. The tensile and shear strength increase at first and then decrease as the quartz fiber content increases from $50 \%$ to $70 \%$. The tensile and shear strength are maximum when the quartz fiber content is $60 \%$.
\end{abstract}

\section{Introduction}

Polyether-ether-ketone, or PEEK for short, is linear aromatic macromolecular compound. The rigid benzene ring and flexible ether bond and carbonyl on the macromolecular chain can be seen from the molecular structure,as shown in Fig .1. PEEK is of good mechanical property, heat resistance (the continuous use temperature of $260^{\circ} \mathrm{C}$ ), corrosion resistance, dimensional stability[1,2]. As thermoplastic resin, PEEK can be formed by the way of extrusion, injection, mould pressing, melt spinning, rotational moulding, etc.

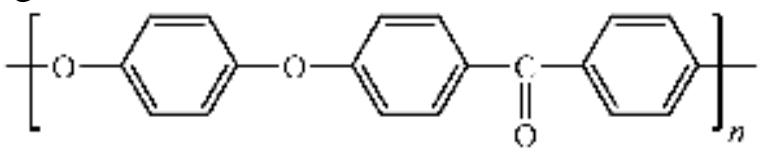

Fig .1 Molecular structure of PEEK

The property of tensile, impact, bending andcroop resistance and the thermal deformation temperature are all improved after PEEK is reinforced by fiberfill. The fiberfill often used in PEEK are carbon fiber, glass fiber and quartz fiber[3].

In recent years, it is becoming a hot point in foreign thermoplastic composite area to develop long fiber-reinforced PEEK, which has a broad application prospect in fields of aerospace, electronic and electrical, medical treatment, energy sources, electric power, machinery, automobile, dope, and so on as its mechanical property is obviously superior to short fiber-reinforced PEEK.

It is difficult to form good impregnation between fiber and resin matrix and make prepregowing to a high melting viscosity of PEEK[4]. In this paper, PEEK fiber and Long-Quartz(short for LQ) are knitted by the way of three-dimension(3D) braid process to preformthat is moulded to bar then, which solves the problem of impregnation between fiber and resin matrix. The effect of compression moulding process on microstructure and mechanical property of continuous long fiber composite material. 


\section{Experimental materials and methods}

PEEK, Jilin University $021 \mathrm{P}$ resin, white granular, melting tempreture of $334^{\circ} \mathrm{C}$; Quartz fiber, Hubei Feilihua Quartz Glass Co., Ltd; Molding press, Y71-100.

PEEK fiber is made from PEEK granular after the processes of drying, heating, melting and spinning. The specification is $0.4 \mathrm{~mm} \times 18$ per single fiber and the linear density is 38.5 tex.

The PEEK and quartz fiber are knitted to 3D five-directional braided composites preform with diameter of $\varphi 5 \mathrm{~mm}$, which is shown in Fig .2. The composite bar with diameter of $\varphi 4 \mathrm{~mm}$ made from preform is obtained after the processes of heating, compression moulding, heat preservation and cooling.

The transverse and vertical microstructure of $\varphi 4 \times 10 \mathrm{~mm}$ bar cut from the composite bar can be observed under Leica DMI5000M optical microscope after the process of mounting, rough grinding, accurate grinding and polishing. Hitachi S450scanning electron microscope is used to observe the impregnation of fiber and resin matrix after the bar specimen is cooled and brittle fractured in liquid nitrogen. The tensile and shear strength of specimen of $\varphi 4 \times 160 \mathrm{~mm}$ cut from the composite bar is measured by CMT5504 universal tensile testing machine.

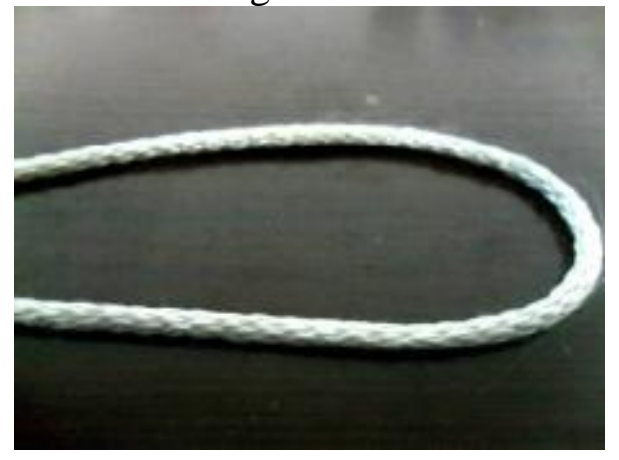

Fig .2 PEEK/LQ 3D-braided prepreg

\section{Results and discussions}

\section{Effect of moulding temperature}

The bar surface blackened after compression moulding at temperature of $400^{\circ} \mathrm{C}$, as shown in Fig .3(a). The reason analyzed was some degree of the resin thermal degradation caused by too high temperature of moulding, which was over melting points $56^{\circ} \mathrm{C}$. A large number of dispersed quartz fiber was found inside the bar on the scanning electron micrograph, asshown in Fig .4(a), which showed bad impregnation between PEEK and quartz fiber at $400^{\circ} \mathrm{C}$. There were two reasons analyzed. On the one hand, it was difficult for the PEEK resin to clad the quartz fiber as resin decomposed at high temperature and lost its original features. On the other hand, volatilizable gas generatedby the resin thermal degradation at the temperature of $400^{\circ} \mathrm{C}$ could not vent in the process of moulding. The composite bar surface didn't blacked and was pale yellow at the moulding temperature of $380^{\circ} \mathrm{C}$, as shown in Fig .3(b), it was uniform and compact in microstructure, there were a lot of PEEK adhering to fiber, which showed that the combination and interface between the fiber and peek were good and high. The reason was that the melting PEEK resin flowed sufficiently without thermal degradation and cladded the quartz fiber well. The microstructure of composite bar moulded at $380^{\circ} \mathrm{Cwas}$ shown in Fig .4(b). 

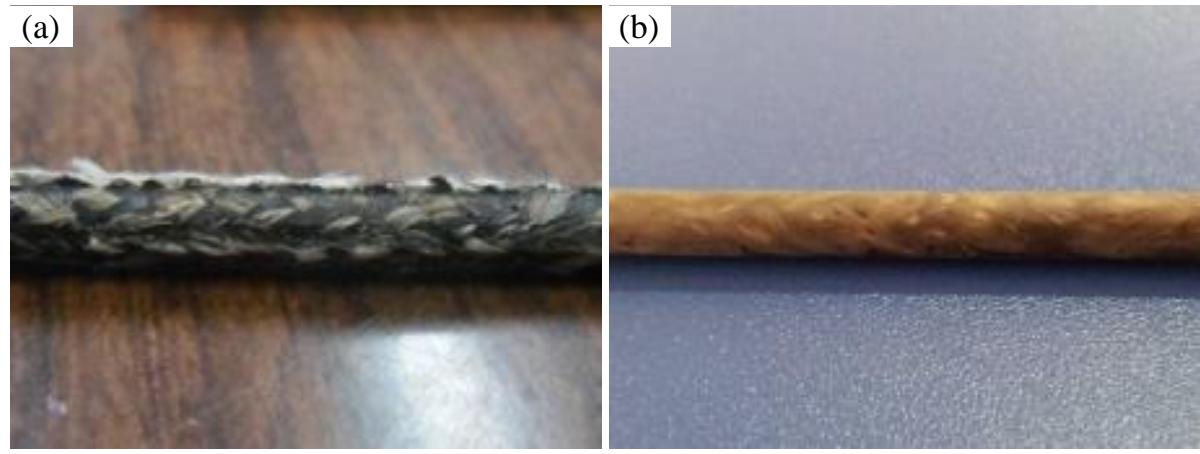

Fig .3 PEEK/LQ bar with different moulding temperatures

(a) $400^{\circ} \mathrm{C}$

(b) $380^{\circ} \mathrm{C}$
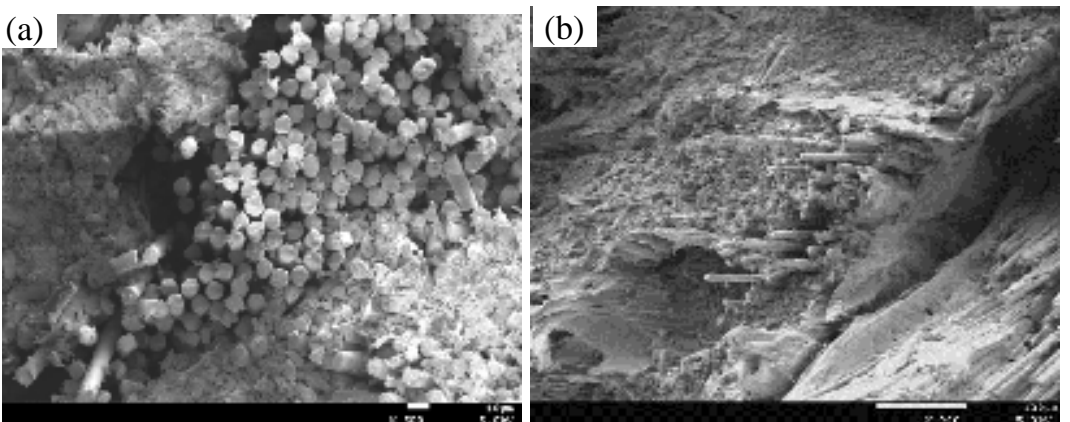

Fig .4 Microstructure of PEEK/LQ bar with different moulding temperatures

(a) $400^{\circ} \mathrm{C}$ (b) $380^{\circ} \mathrm{C}$

\section{Effect of mouldingpressure}

Pressure-holding in moulding process can improve the microstructure compactibility of composites and the mechanical property of bars. The transverse microstructure of bar produced under pressure of $5 \mathrm{MPa}, 10 \mathrm{MPa}$ and $15 \mathrm{MPa}$ at the moulding temperature of $380^{\circ} \mathrm{C}$ is shown in Fig .5, from which it is known that hole defect and dimension decrease as the pressure increases. In Fig. 5(a), Melting PEEK resin cannot dip quartz fiber well as a result of high viscosity and insufficient flow under pressure of $5 \mathrm{MPa}$, It is easy to cause loose of PEEK composited products under low pressure, the material is not quite compact, this affects its mechanical performace. The hot-melt flowability of resin and the impregnation get better when pressure-held at 10MPa in Fig. (b). Though best impregnation is obtained under pressure of 15MPa, a few of holes are observed, which are observed in Fig. 5(c).
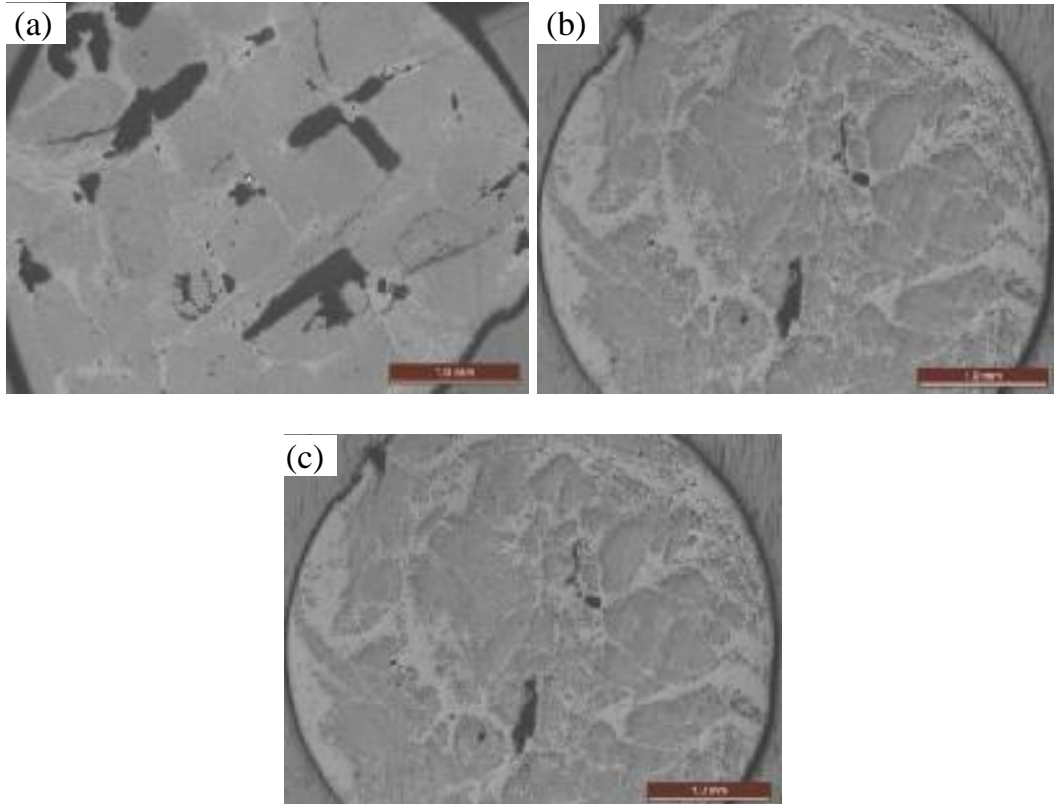

Fig .5 Microstructure of PEEK/LQ bar with different moulding pressures

(a) $5 \mathrm{MPa}$ (b) $10 \mathrm{MPa}$ (c) $15 \mathrm{MP}$ 


\section{Effect of venting}

Internal air vent around as the upper and lower dies go down and up separately when moulding flat plate. However, moulding of composite bar is different. Venting process needs to be involved as the mould of bar surround the prepreg on every side. The surface resin of bar melts first on account of its higher temperature than inner resin, which makes it difficult for the air inside the cylinder to vent. Remained air inside the bar finally forms a hole. As is shown in Fig .5(c), a few of inner holes appear even if the pressure is $15 \mathrm{Mpa}$.

When adding venting process before moulding, the microstructure of bar produced under the moulding temperature of $380^{\circ} \mathrm{C}$ and the pressure of $15 \mathrm{MPa}$ is shown in Fig .6(a), from which compact transverse microstructure and no hole defect can be observed. Fig .6(b) and Fig .6(c) show the magnified transverse and vertical microstructures, in which every dark punctiform quartz fiber strand arranges closely and a mass of light PEEK resin fills among thembecause of long distance between every fiber strand. However, it is difficult to homogenize absolutely as determined by the specialty of 3D-braid process.It is observed that the impregnation is good through further electron microscopy of bar cross-section, as shown in Fig .6(d). The quartz fibers solidify as a whole by gluing of PEEK resin, which improves the mechanical property of bar.
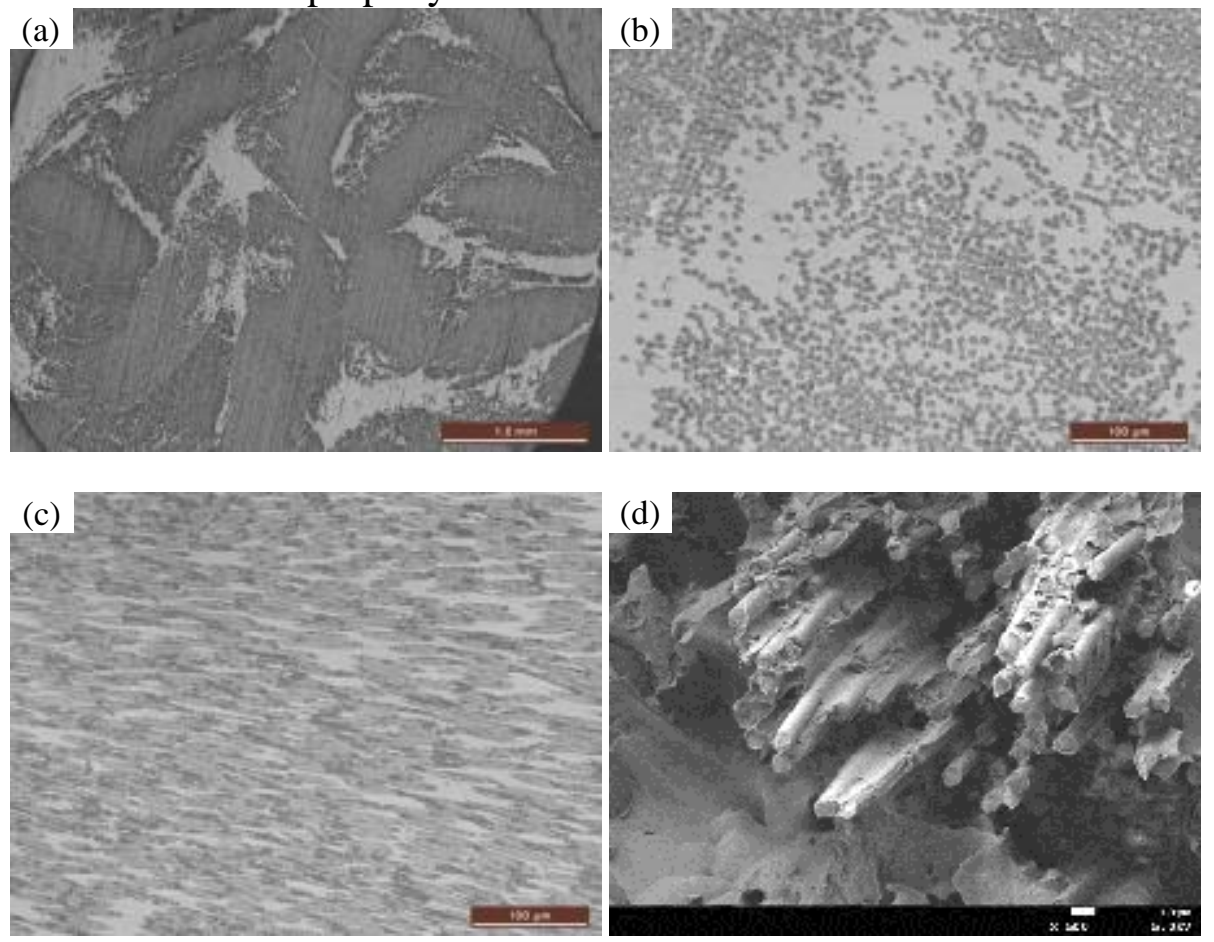

Fig .6 Microstructure of compostieafter adding venting process
(a) Section of OM
(b) Crosswise of OM
(c) Lengthways of OM
(d) Fractograph of SEM

\section{Effect of different fiber content to mechanical property}

The tensile and shear strength of PEEK/LQ bar with different fiber content are listed in Table 1. The maximum tensile and shear strength is up to $628 \mathrm{MPa}$ and $306 \mathrm{MPa}$ separately while the strength of extension of short fiber-reinforced 30\% C/PEEK composite bar is $130 \mathrm{MPa}[5]$. The 3D braided composites is a whole fabric body, which have a high strength, It overcomes the disadvantage of low interlaminar shear strength and also slove the problem for thermoplastic resin impregnant, the level of shear strength is up to alumimum alloy. The strength of PEEK resin improves greatly through continuous long quartz fiber. The tensile and shear strength increase at first and then decrease as the quartz fiber content increases. The effect of fiber bearing capability and strength enhancing get better as the quartz content increases less than or equal to $60 \%$. When the fiber content is over than $60 \%$, reduced resin content results in worse adhesion to quartz fiber and mechanical property of composite bar. In conclusion, the optimum fiber content is $60 \%$. 
Table 1 Mechanical property of PEEK/LQ bar withdifferent fiber content

\begin{tabular}{ccccc}
\hline Number & Braiding technology & $\begin{array}{c}\text { Quartz fiber content } \\
{[\mathrm{wt} . \%]}\end{array}$ & $\begin{array}{c}\text { Shear strength } \\
{[\mathrm{MPa}]}\end{array}$ & $\begin{array}{c}\text { Tensile strength } \\
{[\mathrm{MPa}]}\end{array}$ \\
\hline 1 & & 50 & 252 & 483 \\
2 & 3D five-directional & 60 & 306 & 628 \\
3 & & 70 & 272 & 537 \\
\hline
\end{tabular}

\section{Conclusions}

1. The PEEK/LQ bar surface blackens after compression moulding at temperature of $400^{\circ} \mathrm{C}$ as a result of resin thermal degradation and bad impregnation to quartz fiber. The composite bar surface is pale yellow and PEEK resin clad the quartz fiber wellat the moulding temperature of $380^{\circ} \mathrm{C}$.

2. The internal hole dimension and porosity of composite bar decrease as the holding pressure increases at moulding temperature of $380^{\circ} \mathrm{C}$. Though the densest microstructure is obtained under pressure of $15 \mathrm{Mpa}$, a few of holes are observed.

3. Full impregnation from resin to quartz fiber leads to further decease of internal porosity of bar by adding venting inmoulding process. It is concluded that the optimum moulding process of PEEK/LQ composite bar is at the moulding temperature of $380^{\circ} \mathrm{C}$, pressure of $15 \mathrm{MPa}$ and involving venting.

4. The maximum tensile and shear strength of PEEK/LQ after braiding and moulding process is up to $628 \mathrm{MPa}$ and $306 \mathrm{MPa}$ separately.The tensile and shear strength increase at first and then decrease as the quartz fiber content increases to $50 \%, 60 \%$ and $70 \%$. The strength is maximum when the quartz fiber content is $60 \%$.

\section{References}

[1] X W He, A X Liu, ZH J Zhang: China plastics Industry. Vol. 40(2012), P 1

[2] R CH Chen, H Sun, G Xu: China Plastics. Vol. 40(2012), P 1

[3] Y W Liu. New chemical materials: Vol. 37(2009), P 37

[4] Q F Wang, X D Zhou, J Q Hou: Fiber Composites. Vol. 2(2009), P 43

[5] Y X Lin, CH H Gao: Automobile Technology. Vol. 12(2005), P 37 